\title{
CONHECIMENTO ANTROPOLÓGICO, ARENAS POLÍTICAS, GÊNERO E SEXUALIDADE
}

\author{
ADRIANA PISCITELLI ${ }^{1}$
}

\begin{abstract}
RESUMO
Neste texto dialogo com as discussões sobre as relações entre direitos diferenciados, conflitos e produção de conhecimentos. Com esse fim, realizo alguns comentários sobre as contribuições que a antropologia oferece para compreender como aspectos vinculados a gênero e sexualidade são utilizados como ferramentas políticas, no embate entre certas leituras e concepções sobre esses temas e as aspirações e reivindicações de sujeitos subalternizados pelo exercício da sexualidade. Tomo como referência reivindicações de prostitutas no Brasil, suas relações com grupos feministas e também com 0 Estado, considerando as tensões nessas relações, particularmente, a partir da metade da década de 2000 . Situo esses embates no âmbito da produção de direitos, que tornou possível reivindicar os direitos das mulheres e, nessa esfera, os direitos das prostitutas. Depois descrevo algumas tensões e conflitos entre organizações de prostitutas, grupos feministas e Estado, no Brasil, para abrir para questões que remetem às contribuições da antropologia na produção de conhecimento sobre direitos específicos e sobre as tensões nas arenas políticas vinculadas a debates sobre gênero e sexualidade.
\end{abstract}

\author{
PaLAVRas-ChaVe \\ Direitos diferenciados; Gênero; Sexualidade; Prostituição; Feminismos
}

ANTHROPOLOGICAL KNOWLEDGE, POLITICAL ARENAS, GENDER AND SEXUALITY

\begin{abstract}
In this paper I address the discussions about the relations between different rights, conflicts and the production of knowledge. In order to accomplish that, I make a few comments on the anthropological contributions aimed to the understanding of how gender and sexuality are used as political tools, on how conflictive are certain readings and conceptions about these themes, and also, the aspirations and claims of subjects that are under subalternity by the exercise of their sexuality. I take as a reference the claims of prostitutes in Brazil, their relations with feminist groups and also with the Brazilian government. I consider the tensions in these relations, particularly, from the mid 2000 decade. I place these conflicts in the scope of the production of rights, which made possible to claim for the women's rights, therefore the rights of prostitutes. Then I describe some tensions and conflicts between the organizations of prostitutes, feminist groups and the State in Brazil, in order to open questions that refer to the contributions of anthropology to the production of knowledge about specific rights, and also to approach tensions in the political arenas linked to debates on gender and sexuality.
\end{abstract}

\author{
KEYWORDS \\ Differentiated rights; Gender; Sexuality; Prostitution; Feminisms
}

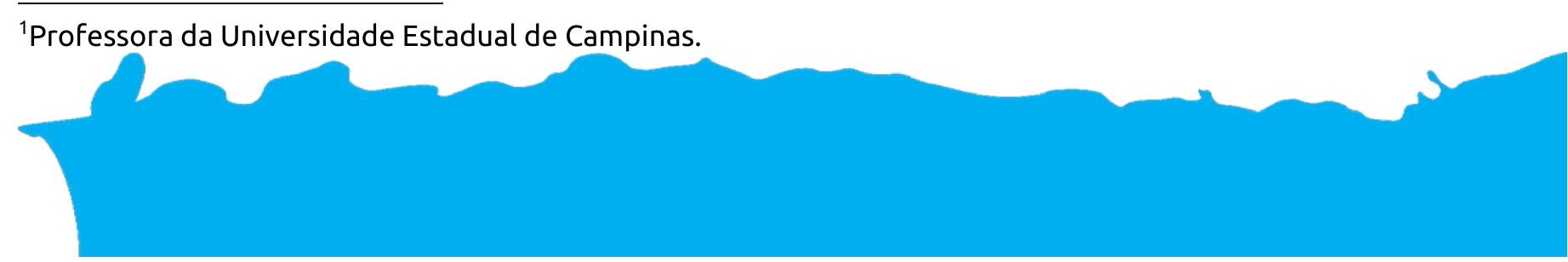




\title{
CONOCIMIENTO ANTROPOLÓGICO, ARENAS POLITICAS, GÉNERO Y SEXUALIDAD
}

\begin{abstract}
RESUMEN
En este texto dialogo con las discusiones sobre las relaciones entre derechos diferenciados, conflictos y producción de conocimientos. Con ese fin, realizo algunos comentarios sobre las contribuciones ofrecidas por la antropología para comprender como aspectos vinculados a género y sexualidad son utilizados como herramientas políticas, en el embate entre algunas lecturas y concepciones sobre esos temas y las aspiraciones y reivindicaciones de sujetos subalternizados por el ejercicio de su sexualidad. Tomo como referencia reivindicaciones de prostitutas en Brasil, sus relaciones con grupos feministas y también con el Estado, considerando las tensiones en esas relaciones, particularmente a partir de la década de 2000 . Situo esos embates en el ámbito de producción de derechos, que tornó posible reivindicar los derechos de las mujeres, y en esa esfera, los derechos de las prostitutas. Describo después algunas tensiones y conflictos entre organizaciones de prostitutas, grupos feministas y Estado, en Brasil, y finalmente considero contribuciones de la antropología en la producción de conocimiento sobre derechos específicos y sobre las tensiones en las arenas políticas vinculadas a los debates sobre género y sexualidad.
\end{abstract}

\section{PALABRAS CLAVE \\ Derechos diferenciados; Género, Sexualidad; Prostitución; Feminismos}

\section{CONNAISSANCE ANTHROPOLOGIQUE, ARÉNAS POLITIQUES, GENRE ET SEXUALITÉ}

Dans cet article, je dialogue avec des discussions sur les relations entre des droits différentiels, les conflits et la production de connaissances. Pour ce fait, je me dédie à analyser des commentaires et des contributions que l'anthropologie offre à la compréhension des aspects liés au genre et à la sexualité et comment ils sont utilisés comme outils politiques dans la lutte entre certaines vues. Il s'agit de problématiser ces questions, les aspirations et les revendications subalternes à l'exercice de la sexualité. J'enquête sur les allégations de prostituées au Brésil, ses relations avec les groupes féministes et de l'État, compte tenu des tensions dans ces relations, en particulier depuis le milieu des années 2000 . Je situe ces luttes dans les droits de production, ce qui a permis faire valoir les droits des femmes et, dans ce domaine, les droits des prostituées. Ensuite, je décris des tensions et des conflits entre les organisations de prostituées, des groupes féministes et de l'État, au Brésil, pour ouvrir aux questions relatives à la contribution de l'anthropologie pour la production de connaissances sur les droits spécifiques et tensions dans les arènes politiques liées aux débats sur le genre et la sexualité.

\section{MOTS-CLÉS}

Droits spécifiques; Genre, Sexualité; Prostitution; Féminisme 


\section{APRESENTAÇÃO}

Em diferentes partes do mundo e também no Brasil os encontros entre "feministas" e "prostitutas" tem sido, com frequência, tensos². Duas cenas que tiveram lugar no país ilustram esses conflitos. A primeira foi no X Encontro Feminista Latino-americano e Caribenho, em 2005, em Serra Negra, no estado de São Paulo. O relato é de Barreto (2015), em sua recente tese sobre prostituição e feminismos em Belo Horizonte. Segundo a autora, numa festa, percebendo a disseminação nesse encontro de ideias a favor da eliminação da prostituição e contrárias a um projeto de lei ${ }^{3}$ que, considerando a prostituição como trabalho, propunha medidas que descriminalizavam o seu entorno, uma prostituta brasileira ${ }^{4}$ subiu ao palco com raiva e declarou: "Sou prostituta e sou feminista!". Ela reivindicava o reconhecimento do movimento de prostitutas como movimento feminista e a ideia de que os direitos das prostitutas são direitos das mulheres.

A outra cena, na qual participei, teve lugar em Salvador, também em 2005, num Encontro que reuniu reconhecidas feministas, acadêmicas e ativistas, incluindo mulheres vinculadas à Central Única dos Trabalhadores/CUT. Essa cena foi marcante. Era a primeira vez que encontrava pessoalmente a Gabriela Leite, fundadora, no final da década de 1980, da primeira organização de prostitutas no Brasil e da Rede Nacional de Prostitutas e que faleceu em 2013. Nesse evento, Gabriela chegou ao salão um par de horas antes de falar e, sentindo que eu era uma aliada, me pediu que a acompanhasse ao bar para beber umas cervejas, para neutralizar o nervosismo que the provocava sentar na mesa com feministas. Ela afirmava ser feminista, mas mais de uma vez se deparou com a aberta rejeição que essa ideia provocava entre feministas. Quando foi sua vez, falou com eloquência durante mais de meia hora, explicando porque a prostituição deve ser considerada um trabalho, detalhando quais eram os aspectos positivos dessa atividade, desde o ponto de vista das prostitutas, e explicando as reivindicações delas. Gabriela era inteligente, rápida, envolvente, carismática. Ela apresentou argumentos consistentes e bem elaborados. Fez rir a plateia e também a comoveu. No entanto, na hora do debate, as feministas da mesa a olharam com uma simpatia condescendente e, desconsiderando sua fala, afirmaram que não podiam apoiá-la porque, embora não estivessem contra as prostitutas, eram, sim, contra a prostituição.

Esses argumentos são recorrentes nas discussões feministas. Gabriela tinha muita experiência. Apesar disso, o seu olhar expressava dor. O que foi marcante para mim, nessa

\footnotetext{
${ }^{2}$ Explico nas próximas páginas porque coloco os dois termos entre aspas.

3 Projeto de lei 98/2003, de Fernando Gabeira.

${ }^{4}$ Nilce Feijó da APPS, da Associação pernambucana de prostitutas (BARRETO, 2015).
} 
cena, foi ver/testemunhar/participar na dolorosa materialização de um processo de subalternização (SPIVAK, 2010). Essas feministas aparentemente deram um lugar a essa mulher, que se apresentou como prostituta, a colocaram na mesa, a deixaram falar e, no entanto, não a "ouviram", no sentido de negarem-lhe qualquer reconhecimento.

Escolhi iniciar este texto com essas cenas porque elas oferecem elementos para refletir sobre as tensões entre feminismos e prostituição e permitem introduzir as questões a partir das quais dialogo com o tema deste dossiê: as relações entre direitos diferenciados, conflitos e produção de conhecimentos. Esabelecerei esse diálogo realizando alguns comentários sobre as contribuições que a antropologia oferece para compreender como aspectos vinculados a gênero e sexualidade são utilizados como ferramentas políticas, no embate entre certas leituras e concepções sobre esses temas e as aspirações e reivindicações de sujeitos subalternizados pelo exercício da sexualidade.

Tomarei como referência as reivindicações de prostitutas no Brasil, suas relações com grupos feministas e também com o Estado, considerando as tensões nessas relações, particularmente, a partir da metade da década de 2000. Este é um momento significativo porque coincide com a difusão de um debate público que tem afetado de diferentes maneiras as dinâmicas do sexo comercial: as discussões e políticas voltadas para o tráfico de pessoas.

Este é o tecido empírico a partir do qual levantarei algumas questões sobre aspectos da produção de conhecimento antropológico nas arenas políticas envolvendo gênero e sexualidade. Começarei situando esses embates no âmbito da produção de direitos, que tornou possível reivindicar os direitos das mulheres e, nessa esfera, os direitos das prostitutas. Depois descreverei, de maneira sintética, algumas tensões e conflitos entre organizações de prostitutas, grupos feministas e Estado, no Brasil. Finalizarei considerando algumas contribuições da antropologia na produção de conhecimento sobre direitos específicos e sobre as tensões nas arenas políticas vinculadas a debates sobre gênero e sexualidade.

\section{A CASCATA DE DIREITOS}

Sobre a noção de direitos, vale retomar alguns pontos levantados por Hunt (2009), no belo livro A invenção dos direitos humanos - uma história. Esse trabalho contribui para pensar nos aspectos que tornam possível a continua diferenciação de direitos, entre eles, a reivindicação, no âmbito dos direitos das mulheres, dos direitos das prostitutas.

Hunt (2009) analisa aspectos da Declaração Universal dos Direitos Humanos, de 1948, na qual se ancoram as reivindicações de direitos contemporâneos, marcando as diferenças, mas também os ecos entre essa declaração e formulações de direitos do século $18^{5}$. Nesse

\footnotetext{
${ }^{5}$ A autora alude à Declaração da Independência dos Estados Unidos, em 1776, universalista no sentido em que afirma que todos os homens são criados iguais, dotados de certos direitos inalienáveis,
} 
contraponto, ela mostra como ao longo desse percurso, a noção de igualdade de direitos, que adquire a qualidade de algo autoevidente, está ancorada num apelo emocional. A autora observa que temos certeza de que um direito humano está em questão quando nos sentimos horrorizados pela sua violação. Uma das características dos direitos humanos é que eles requerem a presença de certo sentimento, partilhado, de indivíduos autônomos, capazes de exercer um julgamento moral - dotados de discernimento para distinguir o bem do mal, e capazes também de sentir empatia pelos outros.

Essa autonomia e empatia, dotadas de emocionalidade, são práticas culturais. E os objetos que mobilizam essa empatia não são fixos. Por esse motivo, os direitos não podem ser definidos de uma vez por todas. Eles permanecem sujeitos a discussão porque a percepção de quem tem direitos e do que são esses direitos vá alterando-se.

Hunt (2009) afirma que, em função destes aspectos, a revolução dos direitos humanos, é por definição, contínua. A Declaração Universal dos Direitos do Homem, delineando obrigações morais para a comunidade mundial e alimentando um consenso internacional sobre a importância de defender os direitos humanos, ofereceu elementos que são acionados no que ela denomina de "cascata de direitos", na constante formulação de direitos específicos. Só que, essa cascata provoca conflitos sobre como ela deve fluir, sobre quais direitos devem ser reconhecidos.

Para entender esses conflitos é importante considerar como os direitos em jogo adquirem força política, como se tornam causas legítimas. Nesse ponto, para pensar nas tensões entre as formulações de direitos de algumas correntes feministas e de organizações de prostitutas, Rubin oferece duas contribuições, formuladas em 1984 e ainda relevantes. Nesse momento, ela chamava a atenção para o fato de que "a sexualidade é política", no sentido de que as formas concretas da sexualidade são permeadas por conflitos de interesses e por manobras políticas. Ela observava, porém, que há momentos históricos em que as disputas em torno da sexualidade são mais acirradas e mais abertamente politizadas. E, de acordo com ela, nesses momentos, o domínio da vida erótica é renegociado.

Segundo Rubin (1984), quando ela estava escrevendo esse texto, na primeira metade da década de 1980, nos Estados Unidos, os conflitos relacionados com os valores sexuais e com o comportamento erótico teriam muito em comum com os conflitos religiosos de séculos anteriores, no sentido de adquirir um imenso peso simbólico. Era um momento de intensa repressão a homossexuais, à prostituição, à obscenidade. Ela percebia analogias entre esses conflitos e o período de final do século XIX na Inglaterra e nos Estados Unidos, em que havia 
campanhas educacionais e políticas para promover a castidade, para eliminar a prostituição e o tráfico de "escravas brancas".

Rubin (1984) delineou uma estratificação sexual presente na sociedade estadunidense da primeira metade da década de 1980, que se tornou famosa. Ela relegava agentes envolvidos em práticas sexuais percebidas como anormais, antinaturais, doentes ou pecaminosas aos graus inferiores dessa hierarquia. Travestis; transexuais; sadomasoquistas; fetichistas; praticantes de sexo com pessoas de outras faixas etárias e de sexo comercial integravam esse grupo. Homossexuais, lésbicas y gays estariam situados em uma faixa intermediária. A autora também mostrou, e isso foi muito importante no âmbito dos debates sobre gênero e sexualidade, como algumas correntes feministas naquele país, envolvidas no que se chamou "as guerras do sexo", sobre pornografia e prostituição, participavam na produção dessa estratificação.

No plano global, os movimentos políticos organizados em torno de algumas destas categorias de pessoas contribuíram de maneira decisiva para situá-las no centro da discussão sobre os direitos humanos e, de maneira mais específica, sobre os direitos sexuais. Esses movimentos pressionam e fazem parte das intensas negociações sociais a respeito da normalização de várias práticas sexuais que, como assinala Duarte (2004), já foram objeto de intensa repressão, como o homoerotismo. Outras, como a violência sexual e a pedofilia, e também o tráfico de pessoas com fins de exploração sexual, tem se tornado objeto privilegiado de criminalização (LOWENKRON, 2015; OLIVEIRA, 2015).

Uns anos atrás, esse autor, e também eu, considerando a visibilidade e força adquirida pelo movimento organizado de prostitutas, pensávamos que estávamos frente a uma relativa normalização da prostituição. No momento atual, porém, tenho mais dúvidas sobre essa normalização. Minhas incertezas têm vinculações com as relações entre prostitutas, feminismos e Estado no Brasil, que comento em seguida ${ }^{6}$.

\section{FEMINISMOS NO BRASIL E PROSTITUIÇÃO}

Em termos das relações entre prostitutas e feministas, as posições atuais de feministas brasileiras abertamente contrárias ao reconhecimento da prostituição como atividade laboral e recusando-se a ouvir as vozes das prostitutas chamam a atenção, quando se leva em conta a maneira como a prostituição foi tratada por integrantes do movimento feminista brasileiro três décadas atrás.

\footnotetext{
6 Observo que há excelentes trabalhos sobre aspectos destas relações, com diversos recortes empíricos, produzidos no país, entre eles os estudos de Tavares (2014; 2015); Barreto (2015), Olivar (2013); Olivar, 2014; Luvolo, 2015; Murray, 2014; Blanchette, Silva, 2016; Sales, 2015; Lenz (2008; 2015).
} 
Quando, no mundo anglo-saxão, as feministas se debatiam nas "guerras do sexo", em torno à pornografia e a prostituição, a organização dos grupos feministas no Brasil girava em torno de outras questões. Levando em conta depoimentos de diversas ativistas, durante as décadas de 1970 e 1980, a prostituição não integrou o leque de principais inquietações no movimento. Esse momento é vinculado à oposição ao regime militar, a lutas pela democratização e pela anistia e também, às "lutas específicas" contra a dominação masculina, enfrentando a violência contra as mulheres e pelo direito ao prazer (PISCITELLI, 2012; 2014; CORRÊA; OLIVAR, 2014).

Setores do movimento feminista e do movimento de mulheres que tinham conexões orgânicas com partidos de esquerda ou as igrejas progressistas consideravam a prostituição como a culminação da exploração capitalista do corpo feminino. Porém, as narrativas de feministas ativas nesse período e de prostitutas sugerem que a prostituição gerava um interesse produtivo. Esse espírito foi registrado por Gabriela Leite. De acordo com ela, os primeiros contatos que teve com as feministas, durante a década de 1980, foram positivos. 0 quadro foi se alterando ao longo do tempo, expressando-se, a partir da década de 1990 ога em aberta rejeição, por parte de feministas que se negavam a ouvir as vozes das prostitutas, ora numa relação ambivalente, em que feministas com importante atuação no cenário nacional afirmavam que a prostituição era uma exploração contra a mulher. Ao mesmo tempo, percebiam posições como as de Gabriela, que afirmava o exercício da prostituição como escolha e como direito, como inquietante, pois era a expressão de um conceito caro ao feminismo: a autonomia.

As leituras ambivalentes e negativas sobre a prostituição se ampliaram a partir do final da década de 1990, no âmbito de reconfigurações do movimento feminista no Brasil que, a partir da redemocratização do País em 1985, envolveram articulações com o Estado e a inserção em organizações não governamentais que se disseminavam no Brasil. Neste contexto se difundiram leituras sobre a prostituição que envolvem uma apreciação consensualmente negativa quando ela era vinculada ao turismo sexual e ao tráfico internacional de pessoas com fins de exploração sexual.

Essas leituras, e as percepções negativas sobre a prostituição, se intensificaram a partir da virada do século, no âmbito da ampliação das articulações feministas transnacionais. De acordo com autoras que estudam a história do movimento feminista no Brasil (MATOS, 2010), a década de 2000 no país é caracterizada pelo trabalho em arenas paralelas de atuação, no âmbito da sociedade civil e nas fronteiras entre ela e o Estado. Ela também é caracterizada pela criação de um novo marco para a atuação do feminismo numa perspectiva transnacional. Esse momento coincide como o surgimento de movimentos de justiça global, envolvendo um leque de atores fora do estado, de redes como a Marcha Mundial das Mulheres contra a Violência e a Pobreza (ALVAREZ, 2009). No Brasil, esses feminismos, conjuntamente com o 
protagonizado por "feministas jovens", isto é, que por primeira vez apresentam uma agenda diferenciada em relação às gerações anteriores, cujas articulações se intensificaram na década de 2010 (FERREIRA, 2016; SORJ, 2016) produziram correntes efervescentes no movimento.

Paralelamente, ao longo das décadas de 2000 e 2010, no Brasil se articulou o movimento contra o tráfico de pessoas associado, sobretudo, à pressão dos movimentos de apoio aos direitos das crianças, e não das mulheres. Essa articulação se produziu num momento no qual o Estado brasileiro, respondendo a pressões políticas transnacionais (CASTILHO, 2015; PISCITELLI, 2008) mas também, segundo Ammar (2013), em parte, pelo interesse do governo de promover o país, no plano internacional, como um modelo de segurança humanitária, concedeu particular relevância ao combate ao tráfico de pessoas, particularmente ao tráfico com fins de exploração sexual, com efeitos na repressão do sexo comercial.

Na década de 2000, o movimento contra o tráfico de pessoas cresceu, alimentado por agências multilaterais internacionais, integrando-se nos regimes transnacionais de direitos humanos, e desembocou na elaboração, da Política Nacional de Enfrentamento ao Tráfico de Pessoas. Esse processo, com participação da Secretaria Especial de Políticas Públicas para as mulheres, incluiu uma ampla consulta à sociedade. Mas, de acordo com integrantes de organizações de prostitutas, elas não foram consideradas.

Ao longo deste percurso, o tráfico de pessoas se tornou um tema de trabalho de importantes coalizões de mulheres brasileiras. Vale observar que o tráfico de pessoas com fins de exploração sexual, articulado no âmbito da violência contra as mulheres, ofereceu uma linguagem para falar de maneira negativa da prostituição, inclusive para feministas que mostravam sua ambivalência sobre a problemática do sexo comercial, isto é, aquelas contrárias à prostituição, mas ambivalentes uma vez que reconheciam autonomia, um valor feminista, nos grupos de prostitutas organizadas.

Articulações feministas brasileiras vinculadas a movimentos transnacionais, que reagem aos efeitos da globalização sobre as mulheres, escolhendo como um dos alvos preferenciais a mercantilização do corpo, passaram a discutir com mais intensidade a prostituição, a partir da preocupação pelo tráfico de pessoas. Nesse contexto, foram realizadas recorrentes fusões entre prostituição, exploração sexual e tráfico de mulheres, nas quais ficava clara a visão negativa da prostituição, considerada como violência sexista, que evocava a ideia de trauma, de sofrimento psicológico e de dor, aspectos que remetem aos aspectos mais eficazes das sensibilizações vinculadas às políticas humanitárias (FASSIN, 2007). E também ficava clara a exigência de algumas feministas de criminalizar o entorno da prostituição. 
Um estudo que coordenei no início da década de 2010 sobre este tema mostrava que essa não era a posição homogênea no movimento feminista no Brasil ${ }^{7}$. Algumas feministas manifestavam um posicionamento intermediário, afirmando a impossibilidade de se opor às prostitutas organizadas que pretendem regulamentar sua profissão e, no entanto, expressando a dificuldade, como feministas com uma atividade que, pensavam, "torna as mulheres objetos". Outras, embora não necessariamente manifestassem isso publicamente, mostravam uma posição mais "aberta", que levava em conta o "empoderamento" de mulheres que exercem a prostituição no Brasil, e a percepção das vantagens dessa atividade em relação a outros serviços mal pagos nos quais elas poderiam estar mais subjugadas.

Essa relativa heterogeneidade também aparecia nas novas expressões do feminismo jovem, como a Marcha das Vadias, e em publicações feministas alternativas na web. A Marcha das Vadias, em torno da luta contra a violência sexista, é organizada por coletivos descentralizados, autônomos, à maneira de coalizões entre pessoas e não de agrupações. No Brasil, foram realizadas Marchas em diversas cidades, adquirindo características específicas em diferentes lugares. Em algumas cidades, as integrantes da Marcha tem tido certo cuidado com a problemática da prostituição, e em algumas cidades, uma real articulação com as organizações de prostitutas (TAVARES, 2015; BARRETO, 2015). E na imprensa alternativa na web, algumas jovens feministas reconhecem a prostituição como trabalho ${ }^{8}$. No entanto, entre as jovens feministas também se difundiu a rejeição à discussão com as prostitutas que afirmam sua atividade como um trabalho, inclusive entre jovens universitárias, como as "anarquistas" que em 2014, ocultando os seus nomes e filiações institucionais, promoveram ataques belicosos contra os/as acadêmicos que discutíamos prostituição no Encontro Fazendo Gênero, em Florianópolis, quando fomos hostilizados com cartazes com frases como: "O que você chama escolha individual nos chamamos de terrorismo heteropatriarcal".

No âmbito dessa heterogeneidade de posições, as articulações com o Estado amplificaram as posições feministas negativas em relação à prostituição. Esclareço que, seguindo a (SHARMA; GUPTA, (2006), penso no Estado como um conjunto de instituições, práticas e pessoas que, permeado por contradições, opera em diferentes dimensões. Neste sentido, um encontro emblemático voltado especificamente para a prostituição, organizado pela Secretaria Especial de políticas para as Mulheres/SPM (2008; 2008a) na segunda metade

\footnotetext{
7 Na pesquisa Tensões no feminismo contemporâneo, desenvolvida no Núcleo de Estudos de Gênero PAGU/Unicamp, apoiada pelo CNPq, concluída em janeiro de 2011, coordenada por mim, participaram lara Beleli, Andressa Passeti de Moura e Andréia Skackauskas Vaz de Mello. Agradeço ao grupo as discussões que informaram muitas das ideias aqui presentes; a Aline Tavares, Carolina Branco e Regina Facchini suas generosas contribuições para pensar nas características que foi assumindo a Marcha das Vadias.
}

\footnotetext{
${ }^{8}$ Ver Marília Moschkovich, O feminismo em disputa, in http/www.outraspalavras.net/2012/03/28/ofeminismo-em-disputa/
} 
da década de 2000, foi interessante. Ele teve o objetivo de planejar posteriormente uma Conferência Nacional que, até o momento, não foi realizada.

Representantes do Estado, vinculados ao Ministério da Saúde e do trabalho manifestavam posições mais próximas da regulação laboral da prostituição que as de várias feministas presentes. Porém, representantes de outro setor do Estado, da Secretaria de Política Públicas para as Mulheres, escolheram as feministas a serem interlocutoras nesse debate sobre políticas públicas voltadas para a prostituição, privilegiando apenas algumas vozes, mais próximas da rejeição da ideia de prostituição como trabalho. Paralelamente, no âmbito de uma aparente neutralidade, a SPM apoiou as iniciativas de alguns grupos feministas e de grupos abolicionistas apoiados pela Igreja Católica. E, ao contrário, grupos de prostitutas organizadas com reivindicações específicas para melhorar as condições de trabalho na prostituição consideram não terem recebido apoio, nem atenção (PISCITELLI, 2012).

Sintetizando o relato que fiz até aqui, embora tenha existido uma relativa heterogeneidade no cenário feminista no Brasil, em termos dos posicionamentos em relação às reivindicações das prostitutas, no âmbito da articulação com feminismos transnacionais e em versões dos feminismos jovens há um acirramento da negação a essas reivindicações. E, na sua articulação com setores do Estado, fazendo parte da arquitetura de governamentalidade (FOUCAULT, 2006) as vozes feministas contrárias ao reconhecimento da prostituição como trabalho foram tornando essas posições crescentemente mais visíveis. E, se em certo momento do debate as discussões feministas no Brasil passaram a prestar mais atenção à prostituição, a partir da preocupação com o tráfico de pessoas, no momento atual a situação mostra indícios de estar alterando-se.

No contexto recente, no âmbito da notável difusão dos regimes de combate ao tráfico de pessoas no Brasil, que tem operado mediante a intensificação de processos de capilarização", levando esse combate às mais diversas "margens" (DAS; POOLE, 2008) do Estado, a noção de tráfico de pessoas foi ampliando-se no debate público (PISCITELLl; LOWENKRON, 2015). Diferentes causas históricas na agenda dos direitos humanos no Brasil, como a luta contra o "trabalho escravo", passaram a utilizar a linguagem do tráfico de pessoas (SPRANDEL, 2016). Os perfis de vítimas e as modalidades de tráfico de pessoas contempladas nas discussões foram se diversificando. Nesse contexto, nos debates feministas, a prostituição e já não o tráfico de pessoas, parece novamente delinear-se como "problema".

Paralelamente, no âmbito da atuação das prostitutas organizadas se registram novos movimentos em relação aos feminismos que redundam na disseminação à oposição entre feminismos e prostituição. Trata-se das reivindicações das "putas-feministas" que, articuladas

\footnotetext{
${ }^{9}$ Considero a categoría capilarização tal como foi elaborada por Michel Foucault (1979:182), aludindo à circulação de fluxos descentralizados de poder que se disseminam no tecido social.
} 
transnacionalmente, questionam frontalmente essa divisão e situam os direitos das prostitutas no âmbito de discussões sobre os direitos das mulheres.

\title{
QUESTIONANDO 0 FEMINISMO DESDE "DENTRO"
}

\author{
"Pausa no corre pra dizer que: \\ o Putafeminismo brasileiro tá sendo parido, \\ e tá sendo arrepiante estar envolvida "nisso tudo" \\ nós estamos fazendo história \\ uau"
} postagem de Monique Prada em sua página no facebook, junho de 2016

No Brasil, décadas atrás, a oposição entre feministas e prostitutas foi desafiada por Gabriela Leite, num momento em que sua afirmação como feminista era vista como provocação em setores do movimento feminista, no Brasil e também no exterior. Nos últimos anos, é possível perceber novos movimentos em relação a essa oposição, no que se refere à recusa a essa divisão por parte de prostitutas e também na recepção a essa posição. De um lado, há uma apropriação estratégica por parte de prostitutas organizadas dos argumentos do Feminismo de Estado. De outro lado, em um movimento também presente em outros países de América Latina, prostitutas organizadas se reivindicam coletivamente como feministas ante feministas. Essas reivindicações provocam rejeições mas também, e essa é a novidade em relação à década anterior, suscitam uma aberta aceitação em alguns espaços feministas no Brasil.

Cito como exemplo do primeiro movimento o pedido da articulação Norte e Nordeste de profissionais do sexo ${ }^{10}$ à Secretaria de Politicas para as mulheres, de agendamento de uma reunião para realizar uma parceria, em janeiro de $2015^{11}$. Esse documento menciona a colaboração de instâncias do governo, como o Departamento de DST, Aids e Hepatites Virais - do Ministério da Saúde. No entanto, solicita uma agenda também com a SPM, com o fim de ampliar as parcerias.

A solicitação é extremamente interessante em termos do apelo ao Feminismo de Estado, porque começa pedindo ajuda à SPM para refletir sobre o ponto central nas divergências entre prostitutas e feministas: a disputa entre a ideia feminista "o corpo me

10 Criada em maio de 2014 em Manaus, conta com a participação da Associação de Prostitutas do Ceará, de Profissionais do Sexo do Maranhão, Associação Pernambucana de trabalhadoras do sexo, profissionais do sexo e congêneres de Rio Grande do Norte, das Prostitutas da Paraíba, de prostitutas do Piauí. Agradeço a Aline Tavares ter me facilitado este documento. Segundo essa antropóloga, integrante de nosso grupo de pesquisa que acompanhou a história dessa solicitação, até a metade de 2015, ela ainda não tinha sido atendida.

${ }^{11}$ Articulação Norte Nordeste de Profissionais do Sexo: Carta à SPM de Maio de 2014. Observo que várias as agrupações que integram essa articulação não faziam parte da Rede brasileira de prostitutas, mas da federação, que não compartilhava todas as reivindicações da Rede. 
pertence" e a reivindicação das prostitutas, vinculada a essa ideia, do direito ao exercício da prostituição. As integrantes da articulação solicitam participar na redação do texto base para a conferência nacional e participar também nas conferências estaduais e municipais de políticas para as mulheres. Elas também desejam que sejam incluídas informações sobre prostitutas no link "Diversidade das Mulheres", da SPM. Como argumento recorrem à ideia de diversidade disseminada pela SPM, no sentido de que as mulheres não constituem um grupo homogêneo, que há diferenças entre elas e que quando as diferenças se tornam desigualdades é necessário ter políticas públicas específicas de promoção de igualdade de direitos. Finalmente, o documento alude a Simone de Beauvoir, quando a articulação solicita ajuda para que as prostitutas possam se ver como sujeitos políticos, politizando os seus atos, o que muitas ainda não teriam conseguido por "não ter muito empoderamento numa ótima mais feminista."

O segundo movimento, também sugestivo e em evidente crescimento, perceptível a partir da metade da década de 2010, remete às novas vozes feministas das prostitutas, que adquirem força no processo de desafiar o feminismo desde "dentro". Ele remete às ações de algumas organizações de prostitutas e de trabalhadoras sexuais que reivindicam ser feministas. Monique Prada, prostituta, ativista digital e presidenta da CUTS (Central Única de Trabalhadoras e Trabalhadores Sexuais) afirma que prostituição e feminismo caminham juntos na luta pelo direito da mulher à sexualidade ${ }^{12}$. Ela considera ser possível ser prostituta e feminista. Procurar essa convergência é o seu objetivo no ativismo digital. Essa ativista argumenta que essa reunião é possível, uma vez que a prostituição é uma forma de afirmar o poder feminino frente às visões conservadores, isto deveria unir as mulheres numa forma de luta que mantém o feminino refém de uma criação social patriarcal. Essas ideias estão presentes no movimento do "puta-feminismo"13.

Este ressurgimento da afirmação de prostitutas como feministas no Brasil está se disseminando rapidamente, num movimento no qual se tornam evidentes alianças entre elas e sectores do movimento feminista, que realizam encontros com "puta-feministas" e solicitam seus escritos para disseminar em meios digitais feministas. O Seminário Nacional Saúde nas

12 Carta Capital, 24/06/2015, in http://www.cartacapital.com.br/sociedade/monique-prada9583.html, consultado em maio de 2016.

13 No texto de Terra Grammont, autora é apresentada como aliada do movimento de prostitutas, descrevendo o que falaram sobre \#PutaFeminismo, publicado na página da CUTS em junho de 2016, o movimento é descrito como organizado por mulheres de diferentes realidades que compartilham seres profissionais do sexo. Entre os seus objetivos contam-se: reivindicar um feminismo que acolha suas demandas; organizar-se em coletivos, que se articulem com os demais movimentos sociais; lutar por melhores condições de trabalho; lutar para combater o estigma que pesa sobre as trabalhadoras sexuais, causador de exclusão social; lutar contra o preconceito que está atrelado ao exercício da prostituição; fortalecer a rede de apoio entre as mulheres para que mais trabalhadoras sexuais possam sair de situações de risco. 
Esquinas que reuniu prostitutas e feministas em Florianópolis/SC, em abril de 2016, realizado em parceria pela Rede Brasileira de Prostitutas e a Rede Feminista de Saúde oferece um exemplo dessas alianças. O documento produzido nesse encontro, a Carta de Santa Catarina, afirma ser fundamental garantir para todas as pessoas que exercem a prostituição o acesso e o gozo dos direitos em todas as políticas públicas com integralidade; a inclusão de prostitutas, mulheres travestis e mulheres transexuais em todos os locais e instâncias de debate e que se instale nacionalmente um debate público para a defesa da regulamentação da prostituição como trabalho. Este documento foi assinado por organizações de prostitutas e por diversos coletivos, fóruns e agrupações feministas de diferentes partes do país, além de contar com o apoio de outros movimentos ${ }^{14}$.

Estes movimentos e sua relativa aceitação são muito recentes. Na percepção de Monique Prada, ela mantém relações com a força do ativismo digital, que torna impossível ignorar certas reivindicações de direitos. É possível considerar também outros elementos para compreender essas alterações na cena política. Um deles é a força adquirida pelo ativismo transnacional de prostitutas. Outro desses elementos é o protagonismo político assumido pelas organizações de prostitutas no Brasil, que adquire particular força no momento delicado, de desestabilização democrática vivido no país, no qual as prostitutas feministas se posicionam em defesa da democracia, contra o machismo e a misoginia, apoiando a permanência da presidenta Dilma ${ }^{15}$.

No entanto, assinalo que a recente disseminação da aceitação das reivindicações das prostitutas é relativa, levando em conta que as alianças entre "putas-feministas" e outros setores do movimento feminista no Brasil coexistem com a persistência dos ataques às reivindicações das prostitutas, marcados pela renovação de uma intensa violência simbólica. Alguns deles mantém relação com a discussão sobre prostituição/turismo sexual, no contexto das próximas Olimpíadas. Outros, com a analogia estabelecida por algumas feministas entre estupro e prostituição no marco das discussões que tiveram lugar em junho de 2016 sobre um estupro coletivo em uma favela de Rio de Janeiro. São dirigidas duras acusações a quem reivindica a regulamentação laboral da prostituição - "quem defende a cafetinagem defende a cultura do estupro"; quem defende a "continuidade da profissionalização do sexo", "defende

\footnotetext{
14 Movimentos de feministas e prostitutas defendem a regulamentação da prostituição em "Carta Santa Catarina". Rede Feminista de Saúde, 10/04/2016, in: http://redesaude.org.br/comunica/sexualidade/seminario-nacional-saude-nas-esquinas-divulgacarta-santa-catarina-que-defende-rea, consultado em junho de 2016.
}

15 Prostituta divulga carta aberta à Dilma Rousseff. Em carta enviada à presidente Dilma Rousseff, Monique Prada, prostituta e líder do sindicato das trabalhadoras sexuais, critica o sexismo presente nos xingamentos feitos contra a mandatária. Pragmatismo Político, 14/05/2016, in http://www.pragmatismopolitico.com.br/2016/05/prostituta-divulga-carta-aberta-a-dilmarousseff.html, consultado em junho de 2016. 
a perpetuação do tráfico de mulheres". Essas acusações, mobilizando as emoções suscitadas pelo estupro coletivo, vão além de negar os direitos reivindicados pelas prostitutas como direitos das mulheres: convertem os objetos dessas reivindicações - descriminalização do entorno da prostituição e regulamentação laboral da prostituição - praticamente em causa da violência contra as mulheres.

Sintetizando, a arena política mostra alterações nas relações entre feminismos e prostituição, no âmbito de sérias modificações no contexto político mais amplo no Brasil. No entanto, isto não elimina os conflitos em torno ao reconhecimento destes direitos específicos. Diria, até, que conjuntamente com as novas alianças entre feministas se produz um acirramento das tensões nas disputas em torno da concessão de legitimidade a esses novos direitos.

\section{CONSIDERAÇÕES FINAIS}

Retomo agora as questões que levantei no início, sobre a produção de conhecimento antropológico, nas arenas políticas envolvendo gênero e sexualidade. Queria primeiro chamar a atenção para uma dificuldade. Ela se refere às diferentes temporalidades que permeiam a produção de conhecimento antropológico sobre direitos específicos e as que permeiam as dinâmicas das arenas políticas. Isto não se limita, claro, a questões envolvendo gênero e sexualidade. Contudo, elas adquirem particular importância se pensamos, seguindo Rubin (1984), que estamos vivendo um desses momentos nos quais os conflitos relacionados com os valores sexuais e com o comportamento erótico adquirem um grande peso simbólico.

A questão é que a dinâmica nessas arenas é muito rápida, os contextos e às vezes também as posições neles se alteram, como vivenciamos nos últimos meses, de maneira extremamente veloz. E a produção de conhecimento antropológico, muitas vezes ancorada no trabalho etnográfico tem outro ritmo, quase artesanal. Isto pode provocar diferentes efeitos nas/nos pesquisadoras/es, ignorar as alterações ou registrá-las obsessivamente, com ansiedade. O nosso trabalho, porém, não é jornalístico. O fato de que os contextos se alterem é absolutamente relevante, porque eles são o marco no qual as ideias fazem sentido (STRATHERN, 1988). Contudo, na análise antropológica a mudança de um contexto não invalida a análise de um período anterior. Ao contrário, oferece elementos para situar em perspectiva as alterações.

A segunda questão se refere ao posicionamento do ou da antropólogo/a nessas arenas. Um dos principais aportes da antropologia é oferecer ferramentas para mapear as noções e pressupostos presentes nas arenas políticas, articulando-os aos diferentes grupos de interesse. No entanto, esta tarefa, exige um posicionamento de quem realiza a pesquisa. Continuo achando que se a antropologia ajuda a relativizar posições, a saída não é um 
perspectivismo absoluto, no qual qualquer noção seja equivalente. A questão, e aqui concordo com Overing (2000), é contextualizar sem relativizar, analisando como as noções de direitos são criadas, possuídas e transformadas no marco de situações complexas.

Nos embates aqui contemplados torna-se evidente que na articulação de lógicas envolvidas, as narrativas sobre direitos das mulheres que prevalecem, ao ignorar as reivindicações das prostitutas, apagam suas ideias e aspirações. Esses embates também colocam questões sobre os aspectos que alimentam esse processo. Vianna (2013) observa que as gramáticas dos direitos são elásticas e oferecem espaços para que novos sujeitos se façam presentes em cenas públicas. Se isto é verdade, essa possibilidade não garante o sucesso ou a eficácia de novas reivindicações como as das prostitutas. Isto conduz a nos perguntar sobre os limites da empatia, quando se trata de sujeitos estigmatizados em função do exercício de sua sexualidade e sobre a mobilização estratégica das emoções, como no caso das recentes discussões sobre cultura do estupro e prostituição, para anular a pretensão à legitimidade dos direitos desses sujeitos.

Finalizando, uma última observação. Nestes temas de trabalho, as antropólogas que nos posicionamos como feministas somos interpeladas por alguns questionamentos particulares. A interação entre pensamento e ação que resulta da articulação entre movimentos sociais e produção acadêmica tem estado permanentemente presente nas discussões das antropólogas feministas, voltadas para uma teoria crítica da produção de desigualdades (DEL VALLE, 2013). No entanto, a partir da década de 2000 algumas autoras têm realizado diversos apelos às antropólogas feministas, para que produzam trabalhos úteis nas lutas de autorrepresentação e determinação dos sujeitos de pesquisa, assumindo um caráter claramente político e de colaboração com as populações estudadas, combinando produção teórica e advocacy participativa (AGGARWAL, 2000).

Só que, mesmo tendo estas intenções de engajamento, trabalhar com temas que, como este, estão no centro de disputas, é arriscado, uma vez que os/as pesquisadores/as somos convertidos em "jogadores no campo", tomando emprestadas palavras de Vianna (2013), às vezes também em direções com as quais não concordamos. Embora nossa intenção seja oferecer elementos para que direitos específicos, de populações estigmatizadas, sejam reconhecidos, não podemos ignorar que nossa contribuição pode ser utilizada por outros lados envolvidos na disputa. E devemos estar preparados para isso. 


\section{REFERÊNCIAS BIBLIOGRÁFICAS}

AGGARWAL, Ravina. "Traversing lines of control: Feminist anthropology today." The Annals of the American Academy of Political and Social Science, v. 571.1, p. 14-29, 2000.

ALVAREZ, Sonia. Beyond NG0-ization? Reflections from Latin America. Development, v. 52, n. 2, p. 175184, 2009.

AMAR, PAUL. The security archipelago. Human-Security States, Sexuality Politics and the End of Neoliberalism. Durham and London: Duke University Press, 2013.

BARRETO, Leticia. Somos sujeitas políticas de nossa própria história: Prostituição e feminismos em Belo Horizonte.. Tese (doutorado Interdisciplinar em Ciências Humanas) Instituto de Filosofia e Ciências Humanas, Universidade Federal de Santa Catarina, 2015.

BLANCHETTE, Thaddeus; SILVA, Ana. "“Brazil has its eye on you": sexual panic and the threat of sex tourism in Rio de Janeiro during the FIFA World Cup, 2014." Brasiliana-Journal for Brazilian Studies, v.4.2, p. 411-454, 2016.

BLANCHETTE, Thaddeus; MURRAY, Laura; RUVOLO, Julie. "Sobre Futebol e Pânicos Morais: Prostituição no Rio de Janeiro durante a Copa do Mundo 2014." Percurso Acadêmico, v. 4, n. 8, p. 188-209, 2015.

CASTILHO, Ela. 'Human Trafficking in Brazil: Between crime-based and human rights-based governance'. Anti-Trafficking Review, v. 4, p. 174-185, 2015. www.antitraffickingreview.org

CORRÊA, Sonia; OLIVAR, José. The politics of prostitution in Brazil between "state neutrality" and "feminist troubles". In: MURTHY, L.; SESHU, M. (Org.). The Business of Sex. Zubaan: New Delhi, 2014, p.175-211.

DAS, Veena. POOLE, Deborah. El estado y sus márgenes. Etnografías comparadas. Cuadernos de Antropología Social, n.27, p.19-52, 2008.

DEL VALLE, Teresa, ed. Gendered anthropology.London: Routledge, 2013.

DUARTE, Luiz Fernando Dias. A Sexualidade nas Ciências Sociais: leitura crítica das convenções. In: PISCITELLI, A. (0rg.). Sexualidade e Saberes: Convenções e Fronteiras. Rio de Janeiro: Garamond Universitária, 2004, p. 39-80.

FASSIN, Didier. Humanitarianism as a Politics of Life. Public culture, n. 19.3, p. 499-520, 2007.

FERREIRA, Carolina. 0 gênero do amor: cultura terapêutica e feminismos. Cadernos Pagu, n. 47, 2016. FOUCAULT, Michel. Microfísica do poder. Edições Graal Rio de Janeiro, 1979.

FOUCAULT, Michel. Seguridad, Territorio, Poblacio[n. Buenos Aires: Fondo de Cultura Econo $\square$ mica, 2006.

HUNT, Lynn: A invenção dos direitos humanos, uma história. São Paulo: Companhia das Letras, 2009.

LENZ, Flavio. Daspú: A moda sem vergonha. Rio de Janeiro: Aeroplano, 2008. 
LENZ, Flavio. Gabriela Leite, prostituta que viveu e promoveu a liberdade. Em Pauta, v. 12, n. 34, p. 209$215,2015$.

LOWENKRON, Laura. 0 monstro contemporâneo: a construção social da pedofilia em múltiplos planos. Rio de Janeiro: EdUERJ 2015.

LOWENKRON, Laura. 0 tráfico de pessoas a partir do olhar policial: Construção de uma categoria criminal e desconstrução de um problema social. Texto apresentado no Seminario: Trânsitos, crime e fronteiras, Campinas, $2015 \mathrm{~b}$.

LUNA SALES, Paula. Sexo transnacional, exploração sexual e turismo em Fortaleza durante a Copa: efeitos das ações contra o tráfico de pessoas sobre as dinâmicas dos mercados do sexo. Texto apresentado no Seminario: Trânsitos, crime e fronteiras, Campinas, 2015.

MATOS, Marlise. Movimento e teoria feminista: É possível reconstruir a teoria feminista a partir do Sul global? Rev. Sociol. Polít. Curitiba, v. 18, n. 36, p. 67-92, 2010.

MURRAY, Laura. Entre "fazer direito" e "direitinho": gesta $\square$ o de Vi $\square$ timas e as poli $\square$ ticas de proteça $\square$ o. Revista Ártemis, v. XVIII, n. 1 p. 28-41, 2014.

OLIVAR, José. Devir puta: políticas da prostituição na experiências de quatro mulheres militantes. Rio de Janeiro: Eduerj, 2013.

OLIVEIRA, Alessandro José. Pedofilias : doenças e delitos. Campinas: Unicamp 2015.

PISCITELLI, Adriana. Entre as "máfias" e a "ajuda": a construção de conhecimento sobre tráfico de pessoas. Cadernos Pagu, v. 31, p. 29-63, 2008.

. Feminismos e Prostituição no Brasil: Uma leitura a partir da Antropologia Feminista. Cuadernos de antropología social, n. 36, p. 11-31, 2012.

.Transnational Sisterhood? Brazilian Feminisms Facing Prostitution. Latin American Policy, v. 5, n. 2, p. 221-235, 2014.

PISCITELLI, Adriana; Lowenkron, Laura. Apresentação: novas flexões no debate sobre tráfico de pessoas no Brasil. Texto apresentado no Seminário, Seminar: Trânsitos, crime e fronteiras, 2015.

RAPPORT, Nigel; OVERING, Joanna. Human Rights. in: Rapport Nigel e Overing Joanna: Social And Cultural Anthropology, the key concepts, New York, Routledge 2000: 162-172.

RUBIN, Gayle. Pensando sobre sexo: Notas para uma teoria radical da política de sexualidade. In: Vance, C. (Org.). Pleasure and Danger: exploring Female Sexuality, 1984.

Secretaria Especial de Políticas Públicas para as mulheres. Workshop prostituição feminina, consolidado dos principais pontos debatidos. Brasília, mimeo, 2008.

Secretaria Especial de Políticas Públicas para as mulheres. Workshop prostituição feminina, Relatório Técnico-descritivo. Brasília, mimeo, 2008 a. 
SHARMA, Aradhana; GUPTA, Akhil. Introduction: Rethinking Theories of the State in an Age of Globalization. In: SHARMA, A.; GUPTA, A. The Anthropology of the State, a reader, Malden, Blackwell Publishing, 2006, pp. 1-42.

SORJ, Bila. Do "pessoal é político" para o "político é pessoal"? Novas tendências no feminismo no Brasil. Texto apresentado no Encontro da Latin American Studies Association, New York, 2016

SPIVAK, Gayatri Chakravorty. Pode o subalterno falar?. Editora UFMG, 2010.

SPRANDEL, Márcia. Vou pra rua e bebo a tempestade: observações sobre os dissabores do guarda-chuva do tráfico de pessoas no Brasil. Cadernos PAGU, n. 47, 2016.

TAVARES, Aline. A organização da zona: notas etnográficas sobre as relações de poder na zona de prostituição de Campinas-Jardim Itatinga. Dissertação de Mestrado em Antropologia Social, Campinas: IFCH/UNICAMP, 2014.

TAVARES, Aline. Movimento Feminista em disputa: paradoxos entre discursos nacionais e práticas regionais acerca do tema da prostituição no Brasil. Texto produzido como produto final do Concurso de Becas Julieta Kirkwood "Movimientos de mujeres y lucha feminista en América Latina y el Caribe",2015.

VIANNA, Adriana. Introdução: fazendo e desfazendo inquietudes no mundo dos direitos. Vianna A, (Org.). 0 fazer e o desfazer dos direitos: experiências etnográficas sobre política, administração e moralidades. Rio de Janeiro: E-papers, 2013, p. 15-35. 